216 G.Kern, T.Popow-Kraupp, M.Kundi, O.Stur, H.Wallner, (introduced by O.Stur), Institute of Virology, University of Vienna, Austria. RESPIRATORY VIRAL INFECTIONS IN YOUNG HOSPITALIZED CHILDREN AND OUTPATIENTS IN AUSTRIA. PRELIMINARY RESULTS OF A LONG TERM STUDY.

Only few data are available on the epidemiology of rhinovirus infections and their contribution to viral respiratory tract infections in tions and their contribution to viral respiratory tract infections in
children. We have therefore started a long term study to investigate the disease incidence in relation to season, age, socioeconomic, environmental, and somatic factors. Nasopharyngeal aspirates were screened for the presence of respiratory syncytial virus (RSV) adenoviruses (AD), parainfluenza virus type I,II,III (PI,II,III) influenza virus type $\hat{A}$ and $B$ (I-A,I-B), enteroviruses (ENT), and rhinoviruses (RIV) by enzyme immunoassay and tissue culture isolation procedure. Preliminary results are as follows: From October 1984 tion procedure. Preliminary results are as follows: From October 1984
to Nlarch 1985, nasopharyngeal aspirates were obtained from 254 to March 1985, nasopharyngeal aspirates were obtained from 254
children (86.2\% hospitalized, $13.8 \%$ outpatients) aged 1 month to $y$ years. In 54.9\% an upper (URI) and in $45.1 \%$ a lower respiratory tract infection (I.P.I) was the reason for medical consultation. $17 \%$ of the URI wcre clue to RSV and $11 \%$ due to RIIV. RSV was recovered in $36.2 \%$ and RHV in $6.7 \%$ of the specimens derived from patients with LRI. Family size had no influence on the attack rate of respiratory tract infections. A higher incidence and a more severe clinical course of respiratory tract disease was found in children exposed to parental smoking. Similar results were obtained in children from families with \& history of chronic respiratory tract disease.

217 A PROSPECTIVE STUDY ON THE INCIDENCE AND EVOLUTION OF CON GENITAL CMV INFECTION IN AN URBAN ITALIAN COMMUNITY.

M. Romano*, M.L. Gabriele*, C. Giaquinto, F. Anglani, P. Falconi, L. Saretta, E. Ruga, G. Errico, G. Largajolli, A. Baroni, R. D'Elia. * Inst. of Hygiene, University of Padova; Dpt. of Pediatric University of Padova - Padova, Italy.

Congenital CMV infection is found in $0.2-2.38$ of newborn infants as reported. These studies, conducted mainly in England and USA, have dealt with populations whose racial origins, socioeconomic status and access to health care programs don t $t$ represent well the situation found in most urban communities of NorthernItaly. Accordingly, we undertook in may 1984 a long term prospective study of the epidemiology of congenital CMV infection in the city of Padova, a community of approximately from babeople in the north-east of ltaly. Urine samples were taken ring he first few tays of ilfe. ring the first few days of life. These urine were collected into virus broblast cultures. Cuv was ida in duplicate into human lung enbryo fi broblast cultures. CMV was identified by the appeareance of the typical cytopatic effect. Congenital infection was diagnosed when CMV was isowere examined for four weeks the first week of life. Negative samples have stuaied 505 full we ne have studied 505 full-term neonates (b.w. $3.340 \mathrm{gr} ; \mathrm{g} . \mathrm{a} .40 \mathrm{wks}$ ), 39 pre
term (b.w. $2.517 \mathrm{gr} ; \mathrm{g} . \mathrm{a} .36 \mathrm{wks}$ ) and 6 small for date neonates (b.w.2328; g.a.39 wks). I out of 550 newborns was found to be congenitally infected, giving a rate of 0.28 , which is similar to the incidence found in northern Europe. At birth the congenitally infected baby had no problems, b.w. Was $3.615 \mathrm{gr}$ and gest.age 40 wks. The infant has beenfollowed up at med to be normal. uny way whe seed to positive for CMV but the baby see so like wise the exact rate of congenital infection in our countrymust be like wise the exact rate of cong
be state after a longer time study.

\section{EFFECT OF AZTREONAM ON AEROBIC FECAL FLORA IN INFANTS}

J.C. Borderon, A. Rastegar, N. Ramponi, F. Gold, Laugier - C.H.U. Tours. France.

Aztreonam, a new monobactam, has a spectrum limited to gram negative aerobic bacilli. To evaluate its effect after parenteral administration on aerobic stool flora (gram negative bacilli, Streptococci D, Staphylococci, Candida), quantitative cultures used serial dilution of stools twice a week on selective media. For gram negative bacilli, agar dishes containing aztreonam or not were used. Colonies of different morphologies were counted. Representatives of each morphological type were then picked for identification and susceptibility tests. Among the 16 patients treated, 12 were decontaminated for aerobic gram negative bacilli by the 3 rd day. Sensitive bacteria persisted in 4 cases, although at a low level Sensitive bacteria persisted in 4 cases, although at a low leve1
$\left(10^{5} / \mathrm{g}\right)$. Resistant bacteria (Enterobacter cloacae and Acinetobacter) appeared at a"normal"level in 2 patients initially decontaminated. No dramatic change could be detected for Streptococci $D$, Staphylococci and Candida. In twelve additional infants neither hospitalized nor treated, no aztreonam resistant gram negative bacilli could be found. OF NEONATAL SEPSIS.

Kafetzis D.A., Giannakopoulou Ch., Papas C., Dellagranmaticas, H.D. 2nd Department of Pediatrics, University of Athens, Greece.

The combination of an aminoglycoside and ampicillin is a commonly used regimen for the initial treatment of neonatal sepsis. Ceftazidime is one of the new cephalosporins, which may have certain advantages for the treatment of neonatal infections. Ve evaluated the efficacy and safety of CF plus flucloxacillin (FL) versus NM plus FL in a randonised comparative study. The addition of FL was decided because of the increased incidence of staphylococcal colonization/infections among the neonates admitted to our NICU the population of which consists only of outborn referrals. Nineteen neonates (10 preterm, 9 term) with clinical signs of infection entered the study protocol. Ten neonates received $\mathrm{CF}+\mathrm{FL}$ and $9 \mathrm{NM}+\mathrm{FL}$. All neonates had abnormal WCC and/or increased CRP value and 8 had positive blood cultures (5 Staph. aureus, 3 E.Coli). Seventeen neonates were cured and 2 died (both of the $\mathrm{NM}+\mathrm{FL}$ group) probably of their underlying disease. No side effects or toxicity attributable to the antibiotic administration were observed. From the results of this small series it appears that the combination of $\mathrm{CF}+\mathrm{FL}$ is effective in treating neonatal sepsis and probably preferable if aminoglycoside blood levels cannot be monitored.

220 Pharmacokinetic of clavulanic acid in newborns and children P. Bégué, B. Quinet, F. Quiniou, J.B. Léauté. Hôp. Trousseau - Paris. France.

Pharmacokinetic of clavulanic acid (C.A.) was studied in newborns and children in combination with amoxicillin (Augmentin) or Ticarcillin (Timentin). Augmentin was administered by $30 \mathrm{mn}$ IV. infusions : $100 \mathrm{mg}$ amox $/ 10 \mathrm{mg} \mathrm{CA} / \mathrm{kg} /$ day before 3 months, $100-200 \mathrm{mg}$ amox. $/ 10-20 \mathrm{mg}$ $\mathrm{CA} / \mathrm{kg} /$ day after 3 months ( 4 infusions in children, 2 infusions in newborn period). Timentin was given identically : $250 \mathrm{mg} \mathrm{TIC} / 10 \mathrm{mg}$ $\mathrm{CA} / \mathrm{kg} /$ day before 3 months, $300 \mathrm{mg}$ TIC $/ 20 \mathrm{mg} \mathrm{CA} / \mathrm{kg} /$ day after 3 months. 8 newborns and 6 children were treated by Augmentin, 3 newborns and 10 children by Timentin. Serum levels were determined by microbiological method. Results are in the table I :

\begin{tabular}{|c|c|c|c|c|c|c|}
\hline \multirow[b]{2}{*}{ CHILDREM } & \multicolumn{2}{|c|}{ AUGMENTIN } & \multicolumn{3}{|c|}{ TIMENIIN } & \\
\hline & $\begin{array}{l}\text { Cmax } \\
4.6 \mathrm{~g} / 1 \\
-0.6\end{array}$ & $\begin{array}{l}T 1 / 2 \beta \\
1.02 \mathrm{~h} \\
-0.47\end{array}$ & $\begin{array}{l}\text { VD } \\
1.1 \\
\pm 0.51 / \mathrm{kg}\end{array}$ & $\begin{array}{l}\text { Cmax } \\
4 .{ }^{\circ} \mathrm{g} / 1 \\
0.6\end{array}$ & $\begin{array}{l}T 1 / 2 \beta \\
1.06 \mathrm{~h} \\
+0.3\end{array}$ & $\begin{array}{l}\text { VD } \\
0.61 \\
-0.2\end{array}$ \\
\hline NEWBORNS & $49 / 1$ & $1.78 \mathrm{~h}$ & $\begin{array}{l}1.1 \\
\pm 0.61 / \mathrm{kg}\end{array}$ & $\begin{array}{l}4.5 \\
\text { to } 5.59\end{array}$ & $1.8 \mathrm{~h}$ & $\begin{array}{l}0.51 \\
\pm 0.15\end{array}$ \\
\hline
\end{tabular}

inhibitor serum level of C.A. active against beta-lactamases. 